\title{
Advantages of 16S rRNA PCR for the diagnosis of prosthetic joint infection
}

\author{
YE $_{\text {ZHANG }}{ }^{1}$, SHUO FENG ${ }^{1}$, WANG CHEN ${ }^{1}$, QING-CHEN ZHANG ${ }^{2}$, SI-FENG SHI ${ }^{1}$ and XIANG-YANG CHEN ${ }^{1}$ \\ ${ }^{1}$ Department of Orthopedic Surgery, Affiliated Hospital of Xuzhou Medical University, \\ Xuzhou, Jiangsu 221002; ${ }^{2}$ Department of Orthopedics, Shandong Provincial Hospital Affiliated to \\ Shandong First Medical University, Jinan, Shandong 250021, P.R. China
}

Received January 15, 2020; Accepted June 24, 2020

DOI: $10.3892 /$ etm.2020.9082

\begin{abstract}
S ribosomal RNA (rRNA) PCR has been reported to be an effective diagnostic means in patients with prosthetic joint infection (PJI). The aim of the present meta-analysis is to establish the overall diagnostic accuracy of the measurement of 16S rRNA PCR for diagnosing PJI. PubMed, Web of Science, Cochrane Library, EMBASE and Wiley Online Library were searched for studies on 16S rRNA PCR in the diagnosis of PJI. The search incorporated all literature published up until December 2018 and the QUADAS-2 checklist were used for quality assessment. The sensitivity, specificity and other measures of accuracy of $16 \mathrm{~S}$ rRNA PCR in the diagnosis of PJI were pooled. Statistical analysis was performed by employing Meta-Disc 1.4 and Stata 12.0 software. A total of 15 studies met the inclusion criteria. The summary estimates for $16 \mathrm{~S}$ rRNA PCR in the diagnosis of PJI in these studies were pooled: Sensitivity, 0.70 (95\% CI, 0.67-0.73); specificity, 0.93 (95\% CI, 0.91-0.94); positive likelihood ratio, 10.93 (95\% CI, 5.55-21.51); negative likelihood ratio, 0.33 (95\% CI, 0.28-0.40); diagnostic odds ratio, 41.77 (95\% CI, 19.90-87.68); and the area under the curve, 0.89 . Subgroup analysis showed that the use of sonicate fluid and periprosthetic tissue has higher sensitivity $(0.76$; $95 \% \mathrm{CI}, 0.69-0.82$; and 0.73 ; $95 \% \mathrm{CI}$, 0.68-0.78, respectively), specificity $(0.93,95 \%$ CI, $0.90-0.96$; and 0.95 ; 95\% CI, 0.90-0.98, respectively) and area under the curve (0.93 and 0.98 , respectively). $16 \mathrm{~S}$ rRNA PCR assay
\end{abstract}

Correspondence to: Dr Si-Feng Shi or Dr Xiang-Yang Chen, Department of Orthopedic Surgery, Affiliated Hospital of Xuzhou Medical University, 99 Huaihai Road, Xuzhou, Jiangsu 221002, P.R. China

E-mail: shisifeng2018@163.com

E-mail: xzchenxiangyang@163.com

Abbreviations: PJI, prosthetic joint infection; PCR, polymerase chain reaction; PLR, positive likelihood ratio; NLR, negative likelihood ratio; DOR, diagnostic odds ratio; CIs, 95\% confidence intervals; SROC, summary receiver operating characteristic curves; AUC, area under the curve

Key words: PCR, 16S rRNA, PJI, diagnosis, meta-analysis plays an important role in the diagnosis of PJI. The results of $16 \mathrm{~S}$ rRNA PCR assays should be interpreted in parallel with clinical findings, the results of microbiological, and other laboratory tests.

\section{Introduction}

Total joint arthroplasty is a safe and effective method that dramatically improves quality of life and restores the function of the patient with arthritis of the hip and knee (1-4). Although its general success is beyond dispute, postoperative complications still accrue, including prosthetic joint infection (PJI), which is an important cause of implant failure and revision arthroplasty should be carried out in most of the cases (5-9). The financial cost is estimated at U.S. \$96,166 per patient requiring revision arthroplasty for infection, which is 4.8 times the cost of a primary arthroplasty $(10,11)$. Due to its insidious onset, early and accurate diagnosis is crucial. Late diagnosis is known to decrease the chance of saving the prosthesis and the joint function, leading to more bone destruction and difficulty in revision surgery (12). Since currently there is no diagnostic gold standard for the identification of PJI, diagnosis is currently based on clinical signs, laboratory and microbiological tests, histopathology and imaging studies (10,13-17). However, aseptic prosthetic loosing may present with similar symptoms as PJI and similar imaging features, which often leads to incorrect diagnosis (18). So, diagnosis of PJI remains a clinical challenge (19).

Laboratory tests including $\mathrm{C}$ reactive protein, erythrocyte sedimentation rate, white blood cells count and gram staining are currently recommended but are not specific, particularly for the early stage of infection $(20,21)$. In the past two decades, new molecular techniques have been applied to PJIs to increase the diagnostic yield including utilizing polymerase chain reaction (PCR) (22). Bacterial ribosomal RNA (rRNA) PCR is reported to be a rapid and more sensitive tool for microbiological diagnosis in most studies, while other studies yielded controversial results $(20,23)$. Previous meta-analysis studies have few references and comparatively little evidence (24). In the present study, new contents were added on the basis of previous studies, including the new studies in the past five years, patients and subgroup analysis. Furthermore, the inclusion criteria were reformulated (16S rRNA was selected as the 
target gene for diagnosis of PJI), and studies using other genes were excluded. Therefore, the purpose of the present study was to perform a meta-analysis to establish the overall diagnostic accuracy of $16 \mathrm{~S}$ rRNA PCR assays for diagnosing PJI.

\section{Materials and methods}

Search strategy. A systemic search of the English medical literature of using 16S rRNA PCR in diagnosis of PJI published between January 1980 and December 2018 was performed. The data collection and reporting was in line with the Preferred Reporting Items for Meta-Analyses (PRISMA) Statement (25). Databases including PubMed (www.ncbi.nlm. nih.gov/pubmed), Web of Science (www.webofknowledge. com), Cochrane Central Register (www.cochranelibrary.com), EMBASE (www.embase.com) and Wiley Online Library of Controlled Trials (onlinelibrary.wiley.com) were used. The search strategy was based on the combination of the terms: i) 'PCR' or 'polymerase chain reaction', 'reverse transcription-PCR', 'real-time PCR'; and ii) 'prosthesis infection' or 'prosthetic joint infection' or 'septic loosening'. Searches were limited to human subjects. Moreover, these searches were supplemented with manual searches of references within the interested published articles to identify additional studies. When necessary, the authors were contacted for more information. Initially, there were no restrictions as to the form of publication in order to achieve a highly sensitive search. However, conference abstracts were excluded due to the limited data presented.

Inclusion criteria and exclusion criteria. Only studies meeting the following criteria were included in this meta-analysis: i) Written in English language; ii) $16 \mathrm{~S}$ rRNA was the targeted gene in the diagnosis of PJI; iii) studies with definite clinical diagnosis of PJI: A sinus tract connected to the prosthesis, purulent fluid visible in the synovial fluid or surgical incision, microbiological cultures positive from at least two samples around the prosthesis and acute inflammation in the histopathological periprosthetic tissue sections; iv) sensitivity and specificity were provided or can be calculated; v) $>10$ patients or samples were included in the study.

Studies that fell under the following conditions were excluded from the present study: i) Studies presenting non-original data, conference abstracts, editorials, reviews, guidelines and studies conducted in animals were excluded; ii) studies with no definite clinical diagnosis of PJI and sensitivity and specificity cannot be determined; iii) PCR assay with other target genes in diagnosis of PJI.

Data extraction and quality assessment. Two authors (YZ and SFS) independently reviewed the titles and abstracts of the relevant articles in light of the inclusion criteria. When an article's abstract fulfilled the criteria, the full text was reviewed. Any disagreement in the selection was resolved by a third author. The main elements extracted included the authors' names, area, study design, clinical sample, study years, sex, blinded status, age, sex and number of patients. In order to evaluate the diagnostic performance, a $2 \times 2$ table including true-positive, false-positive, false-negative and true-negative were used for identifying PJIs. These were derived from the data provided

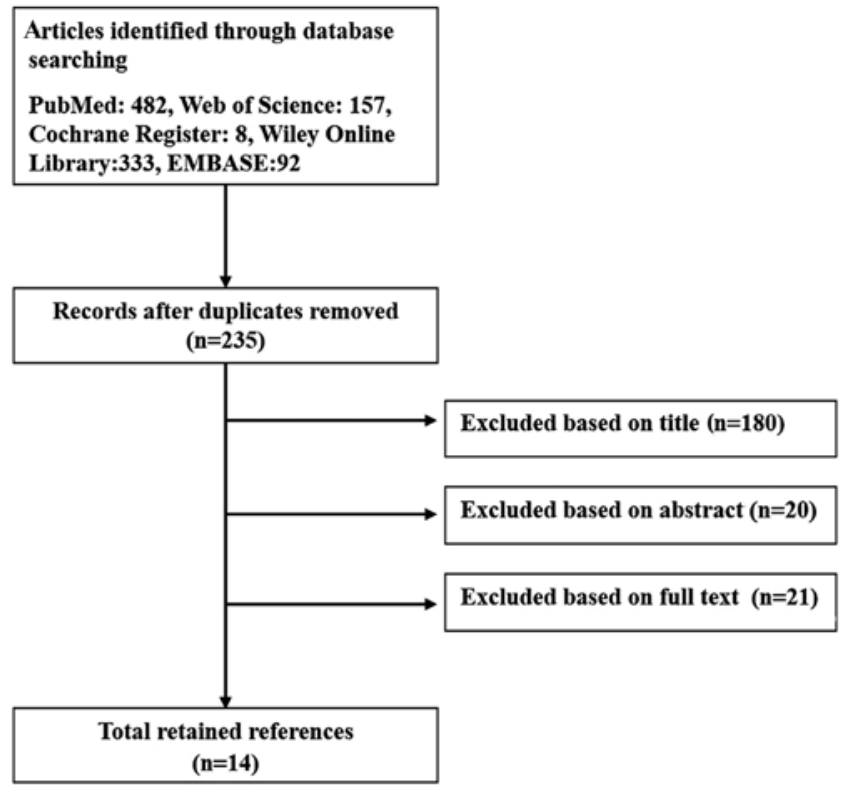

Figure 1. Flowchart showing the selection process of the articles evaluating $16 \mathrm{~S}$ ribosomal RNA PCR assay in patients with prosthetic joint infection.

in the studies. The quality assessment was conducted on all of the included studies. The quality of the included studies was assessed using the diagnostic accuracy study quality tool (QUADAS-2) by Review Manager 5.3 (The Nordic Cochrane Centre, The Cochrane Collaboration).

Statistical analysis. Recommended standard methods for diagnostic meta-analysis were used $(26,27)$. Review Manager 5.3 (The Nordic Cochrane Centre, The Cochrane Collaboration) was used for the quality evaluation and Meta-disc software was used for statistical analysis (version 1.4). Various indexes were calculated including sensitivity, specificity, positive likelihood ratio (PLR), negative likelihood ratio (NLR) and diagnostic odds ratio (DOR) with corresponding $95 \%$ confidence intervals (CIs). A summary of receiver operating characteristic (SROC) curves was obtained to assess the overall performance of the tests by Meta-Disc 1.4. The area under the curve (AUC) displays the trade-off between sensitivity and specificity. An AUC of 1.0 indicates perfect discriminatory ability to distinguish cases from non-cases. The SROC and AUC range between 0 and 1 , with higher values indicating a better test performance $(28,29)$. Statistical heterogeneity was determined by chi-square test and $\mathrm{I}^{2}$. Meta-regression and subgroup analyses were performed to assess potential heterogeneity and Deeks' funnel plot was used to evaluate the publication bias analyzed with Meta-Disc 1.4 and Stata 12.0 (StataCorp LLC). All statistical tests were two-sided, $\mathrm{P}<0.05$ was considered to indicate a statistically significant difference.

\section{Results}

Following independent reviews of the title, abstract and the full text, a total of 14 English language publications (Fig. 1) of studies on 16S rRNA expression for the diagnosis of PJI were included in the present meta-analysis, based on the aforementioned inclusion and exclusion criteria. A publication 


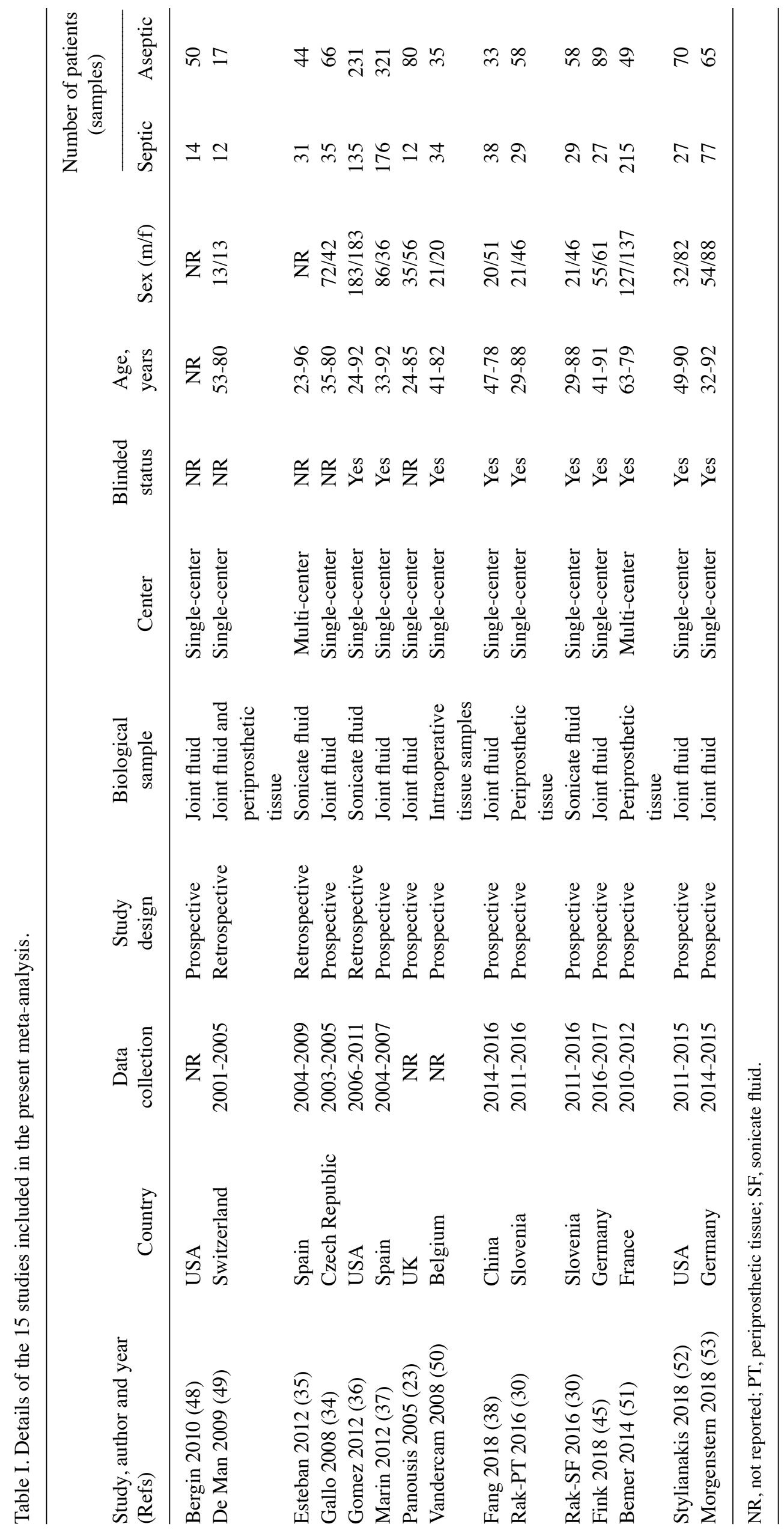


Table II. Data showing true-positives, false-positives, false-negatives and true-negatives, the sensitivities, specificities and the DOR of the 15 studies.

\begin{tabular}{|c|c|c|c|c|c|c|c|}
\hline Study, author and year (Refs) & $\mathrm{Tp}$ & Fp & Fn & Tn & Sensitivity & Specificity & DOR \\
\hline Bergin 2010 (48) & 10 & 0 & 4 & 50 & 0.71 & 1 & 235.67 \\
\hline De Man 2009 (49) & 6 & 1 & 6 & 16 & 0.50 & 0.94 & 16 \\
\hline Esteban 2012 (35) & 26 & 14 & 5 & 30 & 0.84 & 0.68 & 11.14 \\
\hline Gallo 2008 (34) & 25 & 2 & 10 & 64 & 0.71 & 0.97 & 80 \\
\hline Gomez 2012 (36) & 95 & 5 & 40 & 226 & 0.7 & 0.98 & 107.35 \\
\hline Marin 2012 (37) & 119 & 4 & 57 & 317 & 0.68 & 0.99 & 165.45 \\
\hline Panousis 2005 (23) & 11 & 21 & 1 & 59 & 0.92 & 0.74 & 30.9 \\
\hline Vandercam 2008 (50) & 31 & 1 & 3 & 34 & 0.91 & 0.97 & 351.33 \\
\hline Fang 2018 (38) & 28 & 0 & 10 & 33 & 0.74 & 1 & 30.90 \\
\hline Rak-PT 2016 (30) & 22 & 4 & 7 & 54 & 0.76 & 0.93 & 42.43 \\
\hline Rak-SF 2016 (30) & 27 & 4 & 2 & 54 & 0.93 & 0.93 & 182.25 \\
\hline Fink 2018 (45) & 15 & 16 & 12 & 73 & 0.55 & 0.82 & 5.70 \\
\hline Bemer 2014 (51) & 151 & 2 & 64 & 47 & 0.7 & 0.96 & 55.45 \\
\hline Stylianakis 2018 (52) & 16 & 11 & 11 & 59 & 0.59 & 0.84 & 7.80 \\
\hline Morgenstern 2018 (53) & 46 & 7 & 31 & 58 & 0.6 & 0.89 & 12.29 \\
\hline
\end{tabular}

Tp, true positive; Fp, false positive; Fn, false negative; Tn, true negative; Se, sensitivity; Sp, specificity; DOR, diagnostic odds ratios; $\mathrm{PT}$, periprosthetic tissue; SF, sonicate fluid.

by Rak et al (30) used sonication on fluid and tissue samples for the diagnosis of PJI. A total of 15 studies included in the 14 publications enrolled 2,070 patients with an age range of 23-96 years. Table I presents baseline characteristics of these studies including clinical characteristics of the patients. Table II shows true-positive, false-positive, false-negative and true-negative of the 15 studies. A graphical summary of the methodological assessment based on QUADAS-2 quality assessment for the included studies is illustrated and all the included studies demonstrated a relatively low risk of bias and applicability concern (Fig. 2). Significant heterogeneity among studies was detected by sensitivity $\left(\mathrm{I}^{2}=61.1 \%\right)$, specificity $\left(\mathrm{I}^{2}=88.6 \%\right.$, Figs. 3 and 4). This indicates significant heterogeneity between studies. The Spearman correlation coefficient was $0.082(\mathrm{P}=0.771)$, which indicated that the heterogeneity was not caused by threshold effects between the included studies.

The pooled analysis revealed: Sensitivity, 0.70 (95\% CI 0.67-0.73); specificity, 0.93 (95\% CI 0.91-0.94); PLR, 10.93 (95\% CI 5.55-21.51); NLR, 0.33 (95\% CI 0.28-0.40); and DOR, 41.77 (95\% CI 19.90-87.68) (Figs. 3 and 4; Table III). The corresponding SROC (Fig. 5) shows an AUC of 0.89, and the pooled diagnostic accuracy is 0.82 with a standard error of 0.037 , which indicates high overall accuracy of $16 \mathrm{~S}$ rRNA PCR for PJI.

Due to the heterogeneity caused by the non-threshold effects between the included studies, a subgroup analysis was conducted to explore the possible sources of heterogeneity. Subgroup analysis was conducted according to the clinical sample, study design, center, blinded status and country (Table III). In the subgroup of the clinical sample, both sonicated fluids and periprosthetic tissues showed higher sensitivity $(0.76,95 \%$ CI $0.69-0.82$; and $0.73,95 \%$ CI $0.68-0.78$,

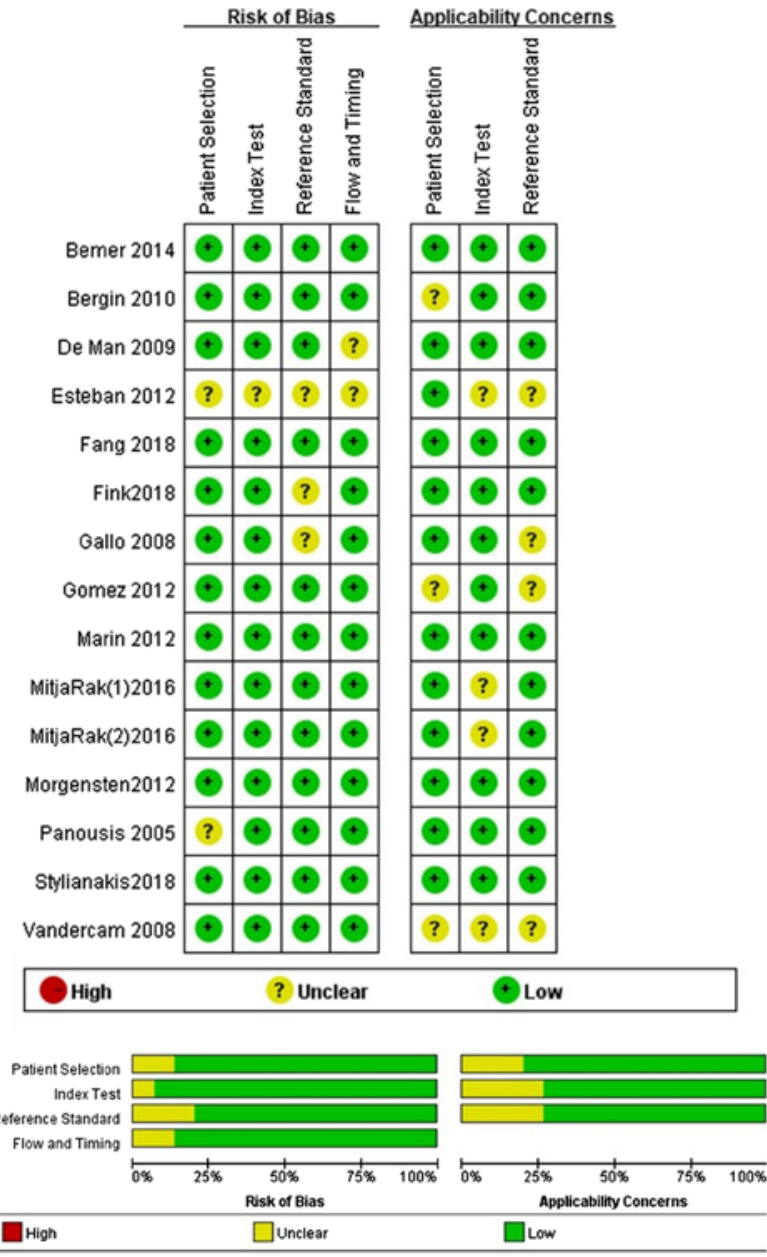

Figure 2. Methodological quality assessment of included studies. PT, periprosthetic tissue; SF, sonicate fluid. High and low represent high and low risk of bias or applicability concern. 


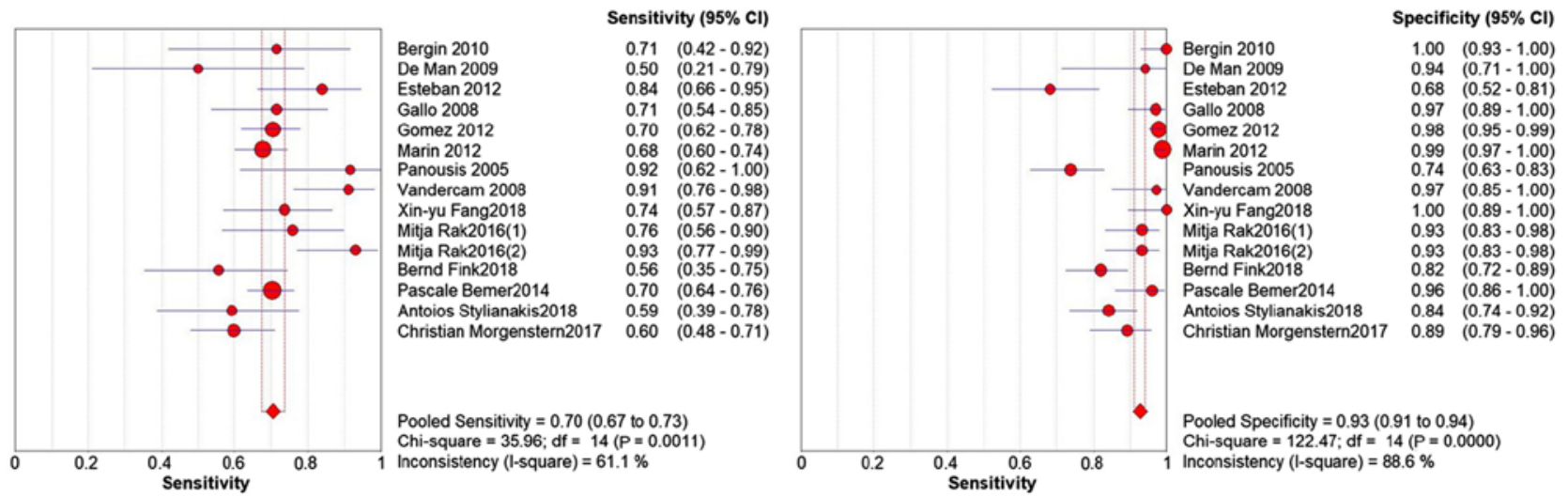

Figure 3. Forest plot for sensitivity and specificity of the 16S ribosomal RNA PCR to diagnose prosthetic joint infection.
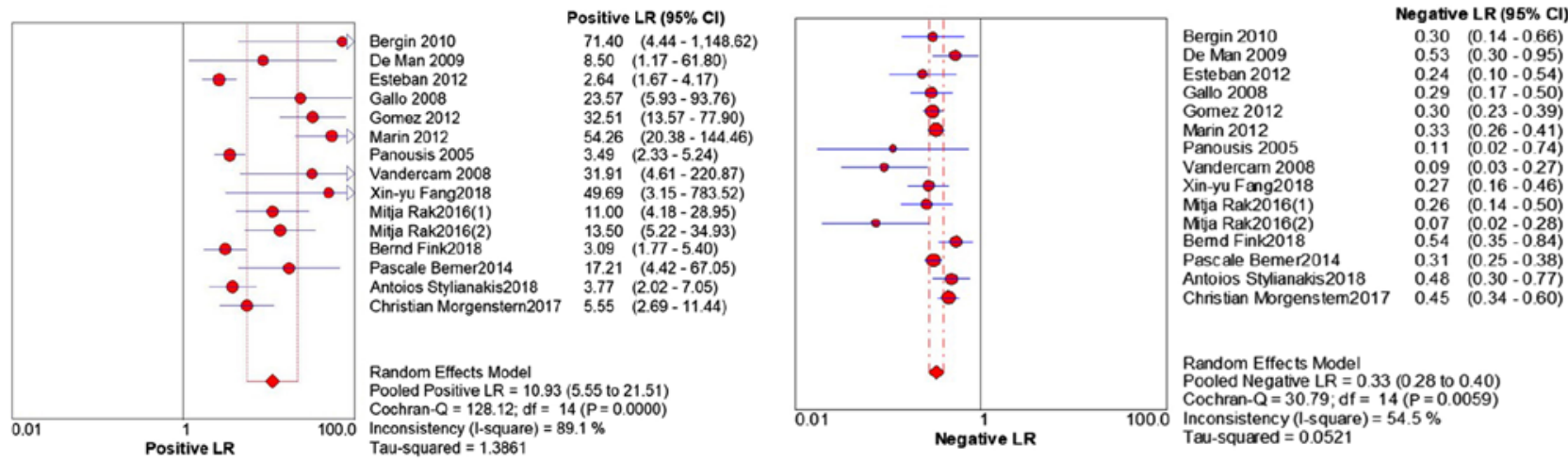

Figure 4. Forest plot for PLR and NLR of the 16S ribosomal RNA PCR to diagnose prosthetic joint infection. PLR, positive likelihood ratio; NLR, negative likelihood ratio.

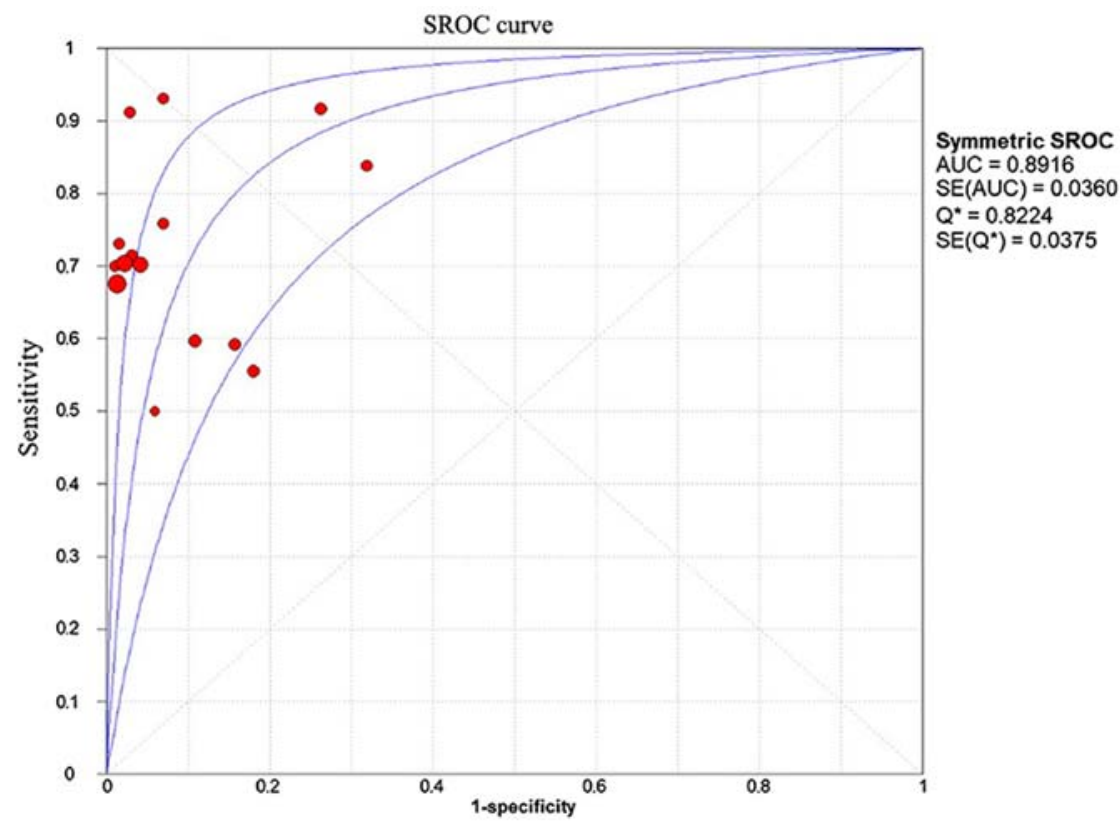

Figure 5. SROC curve for diagnosing a prosthetic joint infection using 16S ribosomal RNA PCR. AUC, area under the curve; SROC, summary receiver operating characteristic; $Q^{*}$, pooled diagnostic accuracy.

respectively) and specificity $(0.93,95 \%$ CI $0.90-0.96 ; 0.95$, 95\% CI 0.90-0.98) compared with joint fluid (sensitivity, 0.67 , 95\% CI 0.62-0.71; specificity, 0.92, 95\%; CI 0.90-0.94). For studies using the blind method, analysis showed a higher specificity and lower sensitivity compared with the studies using the non-blind method (Table III). The analysis results of the 


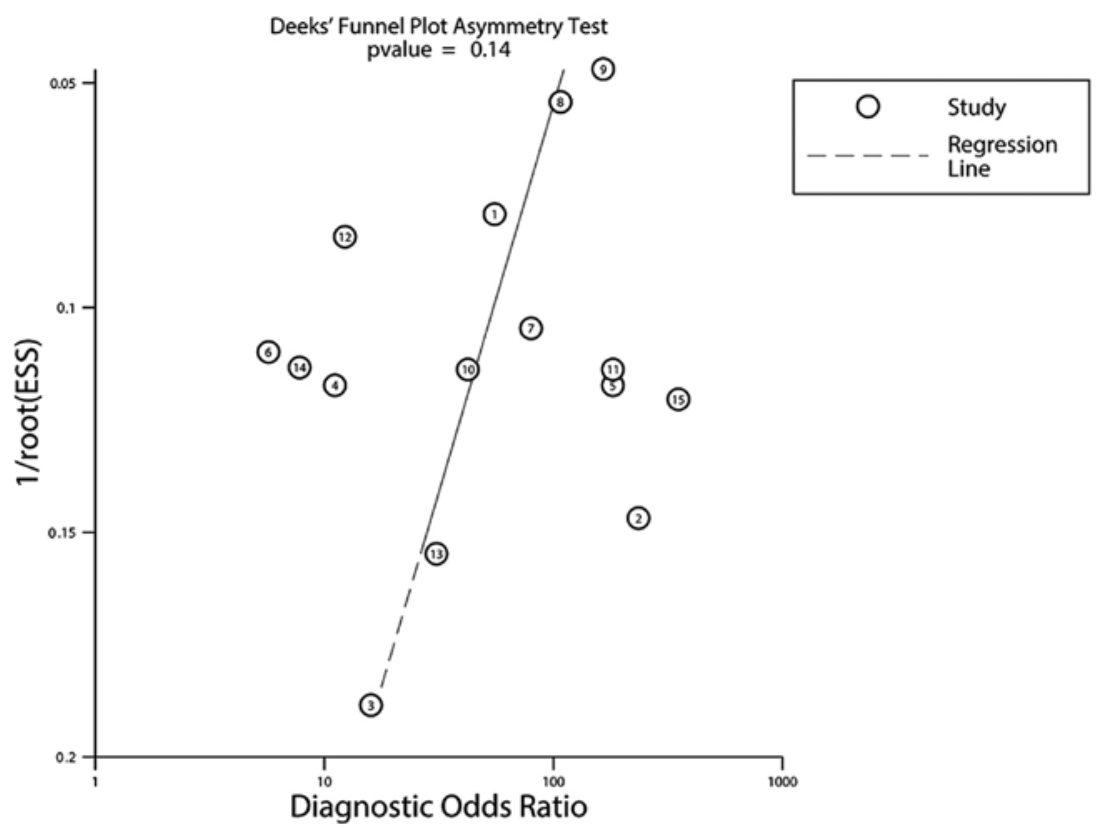

Figure 6. Deeks' funnel chart of the 16S ribosomal RNA PCR to diagnose prosthetic joint infection. ESS, effective sample size.

remaining subgroups showed no significant difference in diagnostic value. The results are shown in Table III. Deeks' funnel chart analysis revealed that there were no notable publication biases in the included studies ( $\mathrm{P}=0.14$; Fig. 6). Studies 2 and 10 had the highest observed specificity, which was indicative of a high test threshold and the highest DOR.

\section{Discussion}

The diagnosis of PJI represents a notable clinical challenge. In recent years, several guidelines have been released for the correct diagnostic approach to this disease (31-38). In the latest guidelines released in 2011, the authors claimed that the diagnosis of PJI is established when one of the following criteria have been fulfilled (32): i) Sinus tract communicating with the prosthesis; ii) a microorganism isolated by culture from at least two separate tissue or fluid samples of affected prosthetic joint; iii) four of the following six criteria exist: iiia) Elevated serum erythrocyte sedimentation rate and elevated serum C-reactive protein concentration; iiib) elevated synovial leukocyte count; iiic) elevated synovial neutrophil percentage; iiid) presence of purulence in the affected joint; iiie) isolation of a microorganism in one culture of periprosthetic tissue or fluid; and iiif) more than five neutrophils per high-power field observed from histologic analysis of periprosthetic tissue at $\mathrm{x} 400$ magnification. Although molecular methods are not included in these criteria and PCR assay is not extensively tested in the routine of a clinical practice, PCR can meet the demanding expectations of the orthopedic community because it is helpful in making an early diagnosis of infection (39-42).

After an extensive evaluation of the literature, fifteen papers were identified on the usefulness of 16S rRNA in diagnosing PJIs. These 15 studies involved 862 PJIs and 1,208 aseptic prostheses. The analysis of these studies shows the sensitivities of 0.70 (range, 0.50-0.93). The false positive PCR results may be due to contamination in the surgery process by skin, vials used for collection of samples or by the presence of $16 \mathrm{~S}$ rRNA from nonviable bacteria present in sterilized medical devices $(23,30,43)$. Contaminants can also be introduced during the PCR reaction by reagents and equipment $(44,45)$. The heterogeneity found by the present meta-analysis was likely due to clinical sample, study design, center, blinded status and the country used for PCR diagnosis. In the clinical sample subgroup, joint fluid samples had a lower sensitivity and specificity compared with all the other groups. Sonicated fluid samples had a higher sensitivity $(0.76 / 0.73)$ and lower specificity (0.93/0.95) compared with the periprosthetic tissue subgroup. A comparison among the different studies showed that significantly heterogeneous specificity values were found in spite of a limited range of pooled specificity value (0.91-0.94). In other subgroups, the sensitivity and specificity were not significantly different. The DOR is the ratio of the odds of a positive test result in patients with the disease relative to the patients without disease; which is a single indicator of test accuracy that combines the data from sensitivity and specificity into a single number. A higher value DOR indicates a better discriminatory test performance. In the present meta-analysis, the present study has found that the mean DOR was 41.77 and this value was 68.15 in periprosthetic tissue sample, which indicated that there was a high level of overall accuracy. But in joint fluid sample, this value was 32.89 which was lower than the mean DOR. In the present study, PLR and NLR were also used for the measurement of diagnostic accuracy. A PLR value of 10.93 suggested that patients with PJIs have a 10 -fold greater chance of having a positive $16 \mathrm{~S}$ rRNA PCR test compared with the controls. NLR is found to be 0.33 in the present meta-analysis, which indicates that if the $16 \mathrm{~S}$ rRNA PCR result is negative for an individual, the probability of this individual having PJI is $33 \%$, which is not low enough to rule out PJI. The SROC approach shows a good overview of the pooled results from several studies. The SROC curve and its AUC demonstrate the tradeoff between sensitivity and 
Table III. Subgroup analyses.

A, Clinical sample

\begin{tabular}{|c|c|c|c|c|c|c|c|}
\hline $\begin{array}{l}\text { Subgroup } \\
\text { analyses }\end{array}$ & Studies, $\mathrm{n}$ & $\begin{array}{l}\text { Sensitivity } \\
(95 \% \mathrm{CI})\end{array}$ & $\begin{array}{l}\text { Specificity } \\
(95 \% \mathrm{CI})\end{array}$ & $\begin{array}{c}\text { PLR } \\
(95 \% \mathrm{CI})\end{array}$ & $\begin{array}{c}\text { NLR } \\
(95 \% \mathrm{CI})\end{array}$ & $\begin{array}{c}\text { DOR } \\
(95 \% \mathrm{CI})\end{array}$ & $\begin{array}{l}\text { AUC } \\
(\mathrm{SE})\end{array}$ \\
\hline $\begin{array}{l}\text { Overall } \\
\text { studies }\end{array}$ & 15 & $\begin{array}{c}0.70 \\
(0.67-0.73)\end{array}$ & $\begin{array}{c}0.93 \\
(0.91-0.94)\end{array}$ & $\begin{array}{c}10.93 \\
(5.55-21.51)\end{array}$ & $\begin{array}{c}0.33 \\
(0.28-0.40)\end{array}$ & $\begin{array}{c}41.77 \\
(19.90-87.68)\end{array}$ & $\begin{array}{l}0.89 \\
(0.0375)\end{array}$ \\
\hline Joint fluid & 8 & $\begin{array}{c}0.67 \\
(0.62-0.71)\end{array}$ & $\begin{array}{c}0.92 \\
(0.90-0.94)\end{array}$ & $\begin{array}{c}10.09 \\
(3.83-26.61)\end{array}$ & $\begin{array}{c}0.38 \\
(0.31-0.64)\end{array}$ & $\begin{array}{c}32.89 \\
(10.73-100.76)\end{array}$ & $\begin{array}{c}0.8128 \\
(0.0794)\end{array}$ \\
\hline $\begin{array}{l}\text { Sonicate } \\
\text { fluid }\end{array}$ & 3 & $\begin{array}{c}0.76 \\
(0.69-0.82)\end{array}$ & $\begin{array}{c}0.93 \\
(0.90-0.96)\end{array}$ & $\begin{array}{c}10.25 \\
(1.45-72.45)\end{array}$ & $\begin{array}{c}0.22 \\
(0.11-0.43)\end{array}$ & $\begin{array}{c}56.78 \\
(10.44-308.89)\end{array}$ & $\begin{array}{c}0.9310 \\
(0.0505)\end{array}$ \\
\hline $\begin{array}{l}\text { Periprosthetic } \\
\text { tissue }\end{array}$ & 3 & $\begin{array}{c}0.73 \\
(0.68-0.78)\end{array}$ & $\begin{array}{c}0.95 \\
(0.90-0.98)\end{array}$ & $\begin{array}{c}14.56 \\
(7.02-30.23)\end{array}$ & $\begin{array}{c}0.22 \\
(0.11-0.44)\end{array}$ & $\begin{array}{c}68.15 \\
(24.43-190.08)\end{array}$ & $\begin{array}{c}0.9860 \\
(0.0304)\end{array}$ \\
\hline
\end{tabular}

B, Study design

\begin{tabular}{|c|c|c|c|c|c|c|c|}
\hline $\begin{array}{l}\text { Subgroup } \\
\text { analyses }\end{array}$ & Studies, $\mathrm{n}$ & $\begin{array}{l}\text { Sensitivity } \\
(95 \% \mathrm{CI})\end{array}$ & $\begin{array}{c}\text { Specificity } \\
(95 \% \text { CI })\end{array}$ & $\begin{array}{c}\text { PLR } \\
(95 \% \mathrm{CI})\end{array}$ & $\begin{array}{c}\text { NLR } \\
(95 \% \mathrm{CI})\end{array}$ & $\begin{array}{c}\text { DOR } \\
(95 \% \mathrm{CI})\end{array}$ & $\begin{array}{l}\text { AUC } \\
(\mathrm{SE})\end{array}$ \\
\hline Prospective & 12 & $\begin{array}{c}0.70 \\
(0.67-0.74)\end{array}$ & $\begin{array}{c}0.93 \\
(0.91-0.94)\end{array}$ & $\begin{array}{c}11.55 \\
(5.47-24.39)\end{array}$ & $\begin{array}{c}0.33 \\
(0.26-0.40)\end{array}$ & $\begin{array}{c}46.64 \\
(19.44-111.87)\end{array}$ & $\begin{array}{c}0.9044 \\
(0.0437)\end{array}$ \\
\hline Retrospective & 3 & $\begin{array}{c}0.71 \\
(0.64-0.78)\end{array}$ & $\begin{array}{c}0.93 \\
(0.90-0.96)\end{array}$ & $\begin{array}{c}8.89 \\
(0.86-91.97)\end{array}$ & $\begin{array}{c}0.34 \\
(0.23-0.51)\end{array}$ & $\begin{array}{c}29.32 \\
(5.36-160.51)\end{array}$ & $\begin{array}{c}0.8766 \\
(0.0359)\end{array}$ \\
\hline \multicolumn{8}{|l|}{ C, Center } \\
\hline $\begin{array}{l}\text { Subgroup } \\
\text { analyses }\end{array}$ & Studies, $\mathrm{n}$ & $\begin{array}{l}\text { Sensitivity } \\
(95 \% \mathrm{CI})\end{array}$ & $\begin{array}{r}\text { Specificity } \\
(95 \% \text { CI })\end{array}$ & $\begin{array}{c}\text { PLR } \\
(95 \% \mathrm{CI})\end{array}$ & $\begin{array}{c}\text { NLR } \\
(95 \% \mathrm{CI})\end{array}$ & $\begin{array}{c}\text { DOR } \\
(95 \% \mathrm{CI})\end{array}$ & $\begin{array}{l}\text { AUC } \\
(\mathrm{SE})\end{array}$ \\
\hline Single-center & 13 & $\begin{array}{c}0.70 \\
(0.66-0.73)\end{array}$ & $\begin{array}{c}0.94 \\
(0.92-0.95)\end{array}$ & $\begin{array}{c}12.21 \\
(5.76-25.87)\end{array}$ & $\begin{array}{c}0.33 \\
(0.27-0.41)\end{array}$ & $\begin{array}{c}46.73 \\
(20.11-108.61)\end{array}$ & $\begin{array}{c}0.9032 \\
(0.0436)\end{array}$ \\
\hline Multi-center & 2 & $\begin{array}{c}0.72 \\
(0.66-0.77)\end{array}$ & $\begin{array}{c}0.83 \\
(0.74-0.90)\end{array}$ & $\begin{array}{c}6.38 \\
(0.44-92.65)\end{array}$ & $\begin{array}{c}0.31 \\
(0.25-0.38)\end{array}$ & $\begin{array}{c}23.68 \\
(4.56-120.92)\end{array}$ & NA \\
\hline
\end{tabular}

$\mathrm{D}$, Blinded status

\begin{tabular}{lccccccc}
\hline $\begin{array}{l}\text { Subgroup } \\
\text { analyses }\end{array}$ & Studies, $\mathrm{n}$ & $\begin{array}{c}\text { Sensitivity } \\
(95 \% \mathrm{CI})\end{array}$ & $\begin{array}{c}\text { Specificity } \\
(95 \% \mathrm{CI})\end{array}$ & $\begin{array}{c}\text { PLR } \\
(95 \% \mathrm{CI})\end{array}$ & $\begin{array}{c}\text { NLR } \\
(95 \% \mathrm{CI})\end{array}$ & $\begin{array}{c}\text { DOR } \\
(95 \% \mathrm{CI})\end{array}$ & $\begin{array}{c}\text { AUC } \\
(\mathrm{SE})\end{array}$ \\
\hline NR & 5 & 0.75 & 0.85 & 6.62 & 0.32 & $\begin{array}{c}30.81 \\
(10.81-87.81)\end{array}$ \\
& & $(0.66-0.83)$ & $(0.80-0.89)$ & $(2.62-16.75)$ & $(0.22-0.48)$ & $(0.0293)$ \\
Yes & 10 & 0.70 & 0.95 & 12.79 & 0.33 & 46.55 & 0.8899 \\
& & $(0.67-0.73)$ & $(0.93-0.96)$ & $(5.74-28.48)$ & $(0.27-0.46)$ & $(17.88-121.20)$ & $(0.0695)$ \\
\hline
\end{tabular}

E, Area

\begin{tabular}{|c|c|c|c|c|c|c|c|}
\hline $\begin{array}{l}\text { Subgroup } \\
\text { analyses }\end{array}$ & Studies, $\mathrm{n}$ & $\begin{array}{l}\text { Sensitivity } \\
(95 \% \text { CI) }\end{array}$ & $\begin{array}{c}\text { Specificity } \\
(95 \% \text { CI })\end{array}$ & $\begin{array}{c}\text { PLR } \\
(95 \% \mathrm{CI})\end{array}$ & $\begin{array}{c}\text { NLR } \\
(95 \% \mathrm{CI})\end{array}$ & $\begin{array}{c}\text { DOR } \\
(95 \% \mathrm{CI})\end{array}$ & $\begin{array}{l}\text { AUC } \\
(\mathrm{SE})\end{array}$ \\
\hline USA and & 4 & 0.70 & 0.96 & 20.90 & 0.33 & 60.50 & 0.5076 \\
\hline Asia & & $(0.63-0.76)$ & $(0.93-0.98)$ & $(3.12-139.86)$ & $(0.26-0.42)$ & $(9.19-398.40)$ & $(0.1565)$ \\
\hline Europe & 11 & $\begin{array}{c}0.71 \\
(0.67-0.74)\end{array}$ & $\begin{array}{c}0.91 \\
(0.89-0.93)\end{array}$ & $\begin{array}{c}9.32 \\
(4.46-19.50)\end{array}$ & $\begin{array}{c}0.32 \\
(0.25-0.41)\end{array}$ & $\begin{array}{c}38.36 \\
(16.47-89.32)\end{array}$ & $\begin{array}{c}0.9072 \\
(0.0344)\end{array}$ \\
\hline
\end{tabular}

PLR, positive likelihood ratio; NLR negative likelihood ratio; DOR, diagnostic odds ratio; AUC, area under the curve; NR, not reported. 
specificity. The data demonstrated that the AUC is 0.90 . The meta-analysis data demonstrated that both the AUC of sonicated fluid samples and periprosthetic tissue samples (0.93 and 0.98 , respectively) were higher than that of total analysis, which indicated a higher level of accuracy. Recently, PCR techniques have shown better value in the diagnosis of PJI (46). PCR theoretically has higher sensitivity and faster test time and is not affected by antibiotics, compared with microbiological cultures. However, the method of sample selection during PCR analysis may affect the capability of diagnosing PJI. Most studies have shown that the sonication of fluid samples can improve the accuracy of PJI diagnosis $(45,47)$. The present results also show that the diagnostic value of ultrasound fluid is significantly higher than that of joint fluid.

PCR is a rapid diagnostic test in the diagnosis of PJI. It is particularly useful in patients who have received antibiotic therapy (19). Bacterial 16S rRNA PCR is a broad-range PCR test, it is the most frequently used molecular diagnostic method in PJI (48-53). There are also other target genes reported in the PCR diagnosis of PJI $(54,55)$. The Mayo clinic's Patel team used metagenomic next-generation sequencing (mNGS) based on Illumina HiSeq 2500 instruments to test the joint fluid and sonicated fluid of patients of revision arthroplasty. They found that mNGS is a powerful tool to identify a wide range of PJI pathogens, including difficult to detect pathogens in culture-negative infections (56). Frank et al (57) used PCR to target the expression of the Staphylococcus aureus icaA gene and the result showed that the presence of icaA in a coagulase-negative staphylococcal isolate associated with an arthroplasty is not a useful diagnostic indicator of pathogenicity. Birmingham et al (58) used reverse transcription-quantitative PCR to detect mRNA encoding for the bacterial genes groEL or femC, and the result showed minimized false-positive detection of nonviable bacteria. Multiplex PCR uses specific primers for a number of microorganisms and allows the detection of multiple pathogens with the one assay. However, the greatest limitation to multiplex PCR is that some organisms are not included in the commercially available kits (59). In addition, both 16S rRNA and other target genes can be used as a valuable method for the diagnosis of PJI. However, microbiological cultures of the sample are also very important, as the antibiotic sensitivity test can be beneficial to the treatment of patients.

This meta-analysis has several limitations. Although a broad search strategy was adopted by two independent reviewers at all stages of the review process, there were only 15 publications included, and the small overall number of patients resulted in wide CIs and may have influenced the outcome. Therefore, it is still difficult to make a definitive conclusion about the accuracy of diagnosis of PJI. Further studies on a large scale may be needed to confirm the diagnostic value of $16 \mathrm{~S}$ rRNA PCR in PJI. Secondly, there is no accepted gold standard, which is a common barrier to all studies for diagnostic accuracy in the detection of PJI. To date, most studies that have examined PJI have relied on diagnosis through clinical manifestations and laboratory tests. There were considerable heterogeneities of the selected studies. Therefore, subgroup analysis was performed to obtain more accurate estimates, and consequently, the findings of this meta-analysis should be interpreted with caution. Finally, during the statistical analysis the Meta-disc software has some advantages over Stata and RevMen in exploration of heterogeneity (for instance, it was able to calculate Chi-square and I-squared) and conduct meta-regression analysis, however as the program also had some inherent statistical shortcomings, the present study also used some functions of the Stata software, such as publication bias.

In conclusion, the present meta-analysis suggests a potential role for $16 \mathrm{~S}$ rRNA PCR in the diagnosis of PJI. The heterogeneity of the studies published until now means that more studies are necessary in order to assess the true accuracy of $16 \mathrm{~S}$ rRNA PCR in the diagnosis of PJI. The results of PCR assays should be interpreted in parallel with clinical findings and the results of microbiological and other laboratory tests.

\section{Acknowledgements}

The authors thank Dr Rui-Qi Li from Beijing Chao-Yang Hospital affiliated to Capital Medical University for valuable technical assistance and support.

\section{Funding}

No funding was received.

\section{Availability of data and materials}

The datasets used and/or analyzed during the current study are available from the corresponding author on reasonable request.

\section{Authors' contributions}

YZ, XYC and SFS conceptualized and designed this study. YZ provided the study materials. YZ, WC and SF collected and assembled the data. YZ and QCZ analyzed and processed the data. All authors wrote the manuscript and approved the final version of the manuscript.

\section{Ethics approval and consent to participate}

Not applicable.

\section{Patient consent for publication}

Not applicable.

\section{Competing interests}

The authors declare that they have no competing interests.

\section{References}

1. Jones CA, Beaupre LA, Johnston DW and Suarez-Almazor ME: Total joint arthroplasties: Current concepts of patient outcomes after surgery. Rheum Dis Clin North Am 33: 71-86, 2007.

2. Lavernia CJ, Guzman JF and Gachupin-Garcia A: Cost effectiveness and quality of life in knee arthroplasty. Clin Orthop Relat Res 134-139, 1997.

3. Pivec R, Johnson AJ, Mears SC and Mont MA: Hip arthroplasty. Lancet 380: 1768-1777, 2012.

4. Van Manen MD, Nace J and Mont MA: Management of primary knee osteoarthritis and indications for total knee arthroplasty for general practitioners. J Am Osteopath Assoc 112: 709-715, 2012 . 
5. Clohisy JC, Calvert G, Tull F, McDonald D and Maloney WJ: Reasons for revision hip surgery: A retrospective review. Clin Orthop Relat Res: 188-192, 2004.

6. Sharkey PF, Hozack WJ, Rothman RH, Shastri S and Jacoby SM: Insall Award paper. Why are total knee arthroplasties failing today? Clin Orthop Relat Res 7-13, 2002.

7. Munjal S, Phillips MJ and Krackow KA: Revision total knee arthroplasty: Planning, controversies, and management-infection. Instr Course Lect 50: 367-377, 2001

8. Mortazavi SM, Molligan J, Austin MS, Purtill JJ, Hozack WJ and Parvizi J: Failure following revision total knee arthroplasty: Infection is the major cause. Int Orthop 35: 1157-1164, 2011.

9. Shi S and Zhang X: Interaction of staphylococcus aureus with osteoblasts (Review). Exp Ther Med 3: 367-370, 2012.

10. Peel TN, Buising KL and Choong PF: Prosthetic joint infection: Challenges of diagnosis and treatment. ANZ J Surg 81: 32-39, 2011.

11. Bozic KJ and Ries MD: The impact of infection after total hip arthroplasty on hospital and surgeon resource utilization. J Bone Joint Surg Am 87: 1746-1751, 2005.

12. Kuo FC, Lu YD, Wu CT, You HL, Lee GB and Lee MS: Comparison of molecular diagnosis with serum markers and synovial fluid analysis in patients with prosthetic joint infection. Bone Joint J 100B: 1345-1351, 2018.

13. Berbari EF, Hanssen AD, Duffy MC, Steckelberg JM, Ilstrup DM, Harmsen WS and Osmon DR: Risk factors for prosthetic joint infection: Case-control study. Clin Infect Dis 27: 1247-1254, 1998.

14. Corvec S, Portillo ME, Pasticci BM, Borens O and Trampuz A Epidemiology and new developments in the diagnosis of prosthetic joint infection. Int J Artif Organs 35: 923-934, 2012.

15. Cobo J and Del Pozo JL: Prosthetic joint infection: Diagnosis and management. Expert Rev Anti Infect Ther 9: 787-802, 2011.

16. Matthews PC, Berendt AR, McNally MA and Byren I: Diagnosis and management of prosthetic joint infection. BMJ 338: b1773, 2009.

17. Tsukayama DT, Goldberg VM and Kyle R: Diagnosis and management of infection after total knee arthroplasty. J Bone Joint Surg Am 85-A(Suppl 1): S75-S80, 2003.

18. Shaw JD, Miller S, Plourde A, Shaw DL, Wustrack R and Hansen EN: Methylene blue-guided debridement as an intraoperative adjunct for the surgical treatment of periprosthetic joint infection. J Arthroplasty 32: 3718-3723, 2017.

19. Peel TN, Buising KL and Choong PF: Diagnosis and management of prosthetic joint infection. Curr Opin Infect Dis 25: 670-676, 2012

20. Cataldo MA, Petrosillo N, Cipriani M, Cauda R and Tacconelli E: Prosthetic joint infection: Recent developments in diagnosis and management. J Infect 61: 443-448, 2010.

21. Ouyang Z, Zhai Z, Qin AN, Li H, Liu X, Qu X and Dai K: Limitations of Gram staining for the diagnosis of infections following total hip or knee arthroplasty. Exp Ther Med 9: 1857-1864, 2015.

22. Patel R, Osmon DR and Hanssen AD: The diagnosis of prosthetic joint infection: Current techniques and emerging technologies. Clin Orthop Relat Res: 55-58, 2005.

23. Panousis K, Grigoris P, Butcher I, Rana B, Reilly JH and Hamblen DL: Poor predictive value of broad-range PCR for the detection of arthroplasty infection in 92 cases. Acta Orthop 76 341-346, 2005.

24. Qu X, Zhai Z, Li H, Li H, Liu X, Zhu Z, Wang Y, Liu G and Dai K: PCR-based diagnosis of prosthetic joint infection. J Clin Microbiol 51: 2742-2746, 2013.

25. Moher D, Shamseer L, Clarke M, Ghersi D, Liberati A, Petticrew M, Shekelle P and Stewart LA; PRISMA-P Group: Preferred reporting items for systematic review and meta-analysis protocols (PRISMA-P) 2015 statement. Syst Rev 4: 1, 2015

26. Devillé WL, Buntinx F, Bouter LM, Montori VM, de Vet HC, van der Windt DA and Bezemer PD: Conducting systematic reviews of diagnostic studies: Didactic guidelines. BMC Med Res Methodol 2: 9, 2002

27. Wang $J$ and Leeflang M: Recommended software/packages for meta-analysis of diagnostic accuracy. J Lab Precision Med 4: 2019.

28. Walter SD: Properties of the summary receiver operating characteristic (SROC) curve for diagnostic test data. Stat Med 21: 1237-1256, 2002.

29. Jones CM and Athanasiou T: Summary receiver operating characteristic curve analysis techniques in the evaluation of diagnostic tests. Ann Thorac Surg 79: 16-20, 2005.
30. Rak M, Kavčlč M, Trebše R and CőR A: Detection of bacteria with molecular methods in prosthetic joint infection: Sonication fluid better than periprosthetic tissue. Acta Orthop 87: 339-345, 2016.

31. Spangehl MJ, Masri BA, O'Connell JX and Duncan CP Prospective analysis of preoperative and intraoperative investigations for the diagnosis of infection at the sites of two hundred and two revision total hip arthroplasties. J Bone Joint Surg Am 81: 672-683, 1999

32. Parvizi J, Zmistowski B, Berbari EF, Bauer TW, Springer BD, Della Valle CJ, Garvin KL, Mont MA, Wongworawat MD and Zalavras CG: New definition for periprosthetic joint infection: From the workgroup of the musculoskeletal infection society. Clin Orthop Relat Res 469: 2992-2994, 2011.

33. Atkins BL, Athanasou N, Deeks JJ, Crook DW, Simpson H, Peto TE, McLardy-Smith P and Berendt AR: Prospective evaluation of criteria for microbiological diagnosis of prosthetic-joint infection at revision arthroplasty. The OSIRIS collaborative study group. J Clin Microbiol 36: 2932-2939, 1998.

34. Gallo J, Kolar M, Dendis M, Loveckova Y, Sauer P, Zapletalova J and Koukalova D: Culture and PCR analysis of joint fluid in the diagnosis of prosthetic joint infection. New Microbiol 31: 97-104, 2008 .

35. Esteban J, Alonso-Rodriguez N, del-Prado G, Ortiz-Pérez A, Molina-Manso D, Cordero-Ampuero J, Sandoval E, Fernández-Roblas R and Gómez-Barrena E: PCR-hybridization after sonication improves diagnosis of implant-related infection. Acta Orthop 83: 299-304, 2012.

36. Gomez E, Cazanave C, Cunningham SA, GreenwoodQuaintance KE, Steckelberg JM, Uhl JR, Hanssen AD, Karau MJ, Schmidt SM, Osmon DR, et al: Prosthetic joint infection diagnosis using broad-range PCR of biofilms dislodged from knee and hip arthroplasty surfaces using sonication. J Clin Microbiol 50: 3501-3508, 2012

37. Marin M, Garcia-Lechuz JM, Alonso P, Villanueva M, Alcalá L, Gimeno M, Cercenado E, Sánchez-Somolinos M, Radice C and Bouza E: Role of universal 16S rRNA gene PCR and sequencing in diagnosis of prosthetic joint infection. J Clin Microbiol 50: 583-589, 2012

38. Fang XY, Li WB, Zhang CF, Huang ZD, Zeng HY, Dong $Z$ and Zhang WM: Detecting the presence of bacterial DNA and RNA by polymerase chain reaction to diagnose suspected periprosthetic joint infection after antibiotic therapy. Orthop Surg 10: 40-46, 2018.

39. Trampuz A, Osmon DR, Hanssen AD, Steckelberg JM and Patel R: Molecular and antibiofilm approaches to prosthetic joint infection. Clin Orthop Relat Res 69-88, 2003.

40. Arciola CR, Collamati S, Donati E and Montanaro L: A rapid PCR method for the detection of slime-producing strains of staphylococcus epidermidis and $\mathrm{S}$-aureus in periprosthesis infections. Diagn Mol Pathol 10: 130-137, 2001.

41. Tarkin IS, Henry TJ, Fey PI, Iwen PC, Hinrichs SH and Garvin KL: PCR rapidly detects methicillin-resistant staphylococci periprosthetic infection. Clin Orthop Relat Res 89-94, 2003.

42. Gallo J, Kolar M, Koukalova D, Sauer P, Loveckova Y and Zapletalova J: P1407. Cultivation versus PCR analysis of joint fluid samples in prosthetic joint infection. Int J Antimicrobial Agents 29: S391-S392, 2007.

43. Clarke MT, Roberts CP, Lee PT, Gray J, Keene GS and Rushton N: Polymerase chain reaction can detect bacterial DNA in aseptically loose total hip arthroplasties. Clin Orthop Relat Res 132-137, 2004

44. Millar BC, Xu J and Moore JE: Risk assessment models and contamination management: Implications for broad-range ribosomal DNA PCR as a diagnostic tool in medical bacteriology. J Clin Microbiol 40: 1575-1580, 2002.

45. Fink B, Steurer M, Hofäecker S, Schäfer P, Sandow D, Schuster P and Oremek D: Preoperative PCR analysis of synovial fluid has limited value for the diagnosis of periprosthetic joint infections of total knee arthroplasties. Arch Orthop Trauma Surg 138: 871-878, 2018.

46. Mariaux S, Tafin UF and Borens O: Diagnosis of persistent infection in prosthetic two-stage exchange: PCR analysis of sonication fluid from bone cement spacers. J Bone Jt Infect 2: 218-223, 2017.

47. Sebastian S, Malhotra R, Sreenivas V, Kapil A, Chaudhry R and Dhawan B: Utility of $16 \mathrm{~S}$ rRNA PCR in the synovial fluid for the diagnosis of prosthetic joint infection. Ann Lab Med 38: 610-612, 2018. 
48. Bergin PF, Doppelt JD, Hamilton WG, Mirick GE, Jones AE, Sritulanondha S, Helm JM and Tuan RS: Detection of periprosthetic infections with use of ribosomal RNA-based polymerase chain reaction. J Bone Joint Surg Am 92: 654-663, 2010.

49. De Man FHR, Graber P, Lüem M, Zimmerli W, Ochsner PE and Sendi P: Broad-range PCR in selected episodes of prosthetic joint infection. Infection 37: 292-294, 2009.

50. Vandercam B, Jeumont S, Cornu O, Yombi JC, Lecouvet F, Lefèvre P, Irenge LM and Gala JL: Amplification-based DNA analysis in the diagnosis of prosthetic joint infection. J Mol Diagn 10: 537-543, 2008.

51. Bemer P, Plouzeau C, Tande D, Léger J, Giraudeau B, Valentin AS, Jolivet-Gougeon A, Vincent P, Corvec S, Gibaud S, et al: Evaluation of $16 \mathrm{~S}$ rRNA gene PCR sensitivity and specificity for diagnosis of prosthetic joint infection: A prospective multicenter cross-sectional study. J Clin Microbiol 52: 3583-3589, 2014.

52. Stylianakis A, Schinas G, Thomaidis PC, Papaparaskevas J Ziogas DC, Gamaletsou MN, Daikos GL, Pneumaticos S and Sipsas NV: Combination of conventional culture, vial culture, and broad-range PCR of sonication fluid for the diagnosis of prosthetic joint infection. Diagn Microbiol Infect Dis 92: 13-18, 2018.

53. Morgenstern C, Cabric S, Perka C, Trampuz A and Renz N: Synovial fluid multiplex PCR is superior to culture for detection of low-virulent pathogens causing periprosthetic joint infection. Diagn Microbiol Infect Dis 90: 115-119, 2018.

54. Arciola CR, Campoccia D, Baldassarri L, Donati ME, Pirini V, Gamberini S and Montanaro L: Detection of biofilm formation in Staphylococcus epidermidis from implant infections. Comparison of a PCR-method that recognizes the presence of ica genes with two classic phenotypic methods. J Biomed Mater Res Part A 76: 425-430, 2006.
55. Montanaro L, Arciola CR, Borsetti E, Brigotti $M$ and Baldassarri L: A polymerase chain reaction (PCR) method for the identification of collagen adhesin gene (CNA) in staphylo coccus-induced prosthesis infections. New Microbiol 21: 359-363, 1998.

56. Miao Q, Ma Y, Wang Q, Pan J, Zhang Y, Jin W, Yao Y, Su Y, Huang Y, Wang M, et al: Microbiological diagnostic performance of metagenomic next-generation sequencing when applied to clinical practice. Clin Infect Dis 67(Suppl 2): S231-S240, 2018.

57. Frank KL, Hanssen AD and Patel R: icaA is not a useful diagnostic marker for prosthetic joint infection. J Clin Microbiol 42: 4846-4849, 2004.

58. Birmingham P, Helm JM, Manner PA and Tuan RS: Simulated joint infection assessment by rapid detection of live bacteria with real-time reverse transcription polymerase chain reaction. J Bone Joint Surg Am 90: 602-608, 2008.

59. Portillo ME, Salvadó M, Sorli L, Alier A, Martínez S, Trampuz A, Gómez J, Puig L and Horcajada JP: Multiplex PCR of sonication fluid accurately differentiates between prosthetic joint infection and aseptic failure. J Infect 65: 541-548, 2012.

This work is licensed under a Creative Commons Attribution-NonCommercial-NoDerivatives 4.0 International (CC BY-NC-ND 4.0) License. 